\title{
QBBEP
}

\section{Reflexões a respeito do uso da modelagem matemática em aulas nos anos iniciais do ensino fundamental}

Emerson Tortola

Lourdes Maria Werle de Almeida

\section{Resumo}

As discussões sobre o uso da modelagem matemática têm revelado que atividades desse tipo podem atender a interesses e necessidades da formação matemática dos estudantes na contemporaneidade - no que diz respeito à avaliação da aprendizagem dos alunos mediante essas atividades, entretanto, ainda há inquietações. Compartilhando destas, apresentamos resultados decorrentes de uma pesquisa em que alunos que participaram do desenvolvimento de atividades de modelagem matemática foram submetidos, um ano após esse desenvolvimento, à resolução de questões em que os conteúdos que emergiram daquelas atividades estavam envolvidos. A pesquisa está associada ao Programa Observatório da Educação e apresenta reflexões acerca do desempenho de estudantes do $5^{\circ}$ ano do ensino fundamental ao realizarem questões vinculadas à Prova Brasil, instrumento utilizado pelo Instituto Nacional de Estudos e Pesquisas Educacionais Anísio Teixeira (Inep) como base de cálculo para obtenção do Índice de Desenvolvimento da Educação Básica (Ideb). Os resultados apontam para o potencial da modelagem matemática em abordar conteúdos curriculares, propostos pelos Parâmetros Curriculares Nacionais (PCN), e sinalizam a aprendizagem dos estudantes, em particular, nos anos iniciais do ensino fundamental.

Palavras-chave: educação matemática; anos iniciais; modelagem matemática; Prova Brasil; Ideb; Observatório da Educação. 


\section{Abstract \\ Reflections on the use of mathematical modeling in classes of the first years of elementary school}

Discussions about the use of mathematical modeling have revealed that some activities can meet the needs and interests of mathematical education of contemporary students. However, there are still concerns regarding the evaluation of students learning through these activities. Thus, we present results from a survey whose students participated in the development of mathematical modeling activities, and one year later, started the resolution of questions related to those previous activities. The research is associated with the Observatory of Education Program and presents reflections on the performance of $5^{\text {th }}$ grade students from elementary school when answering questions from Brazil Test, an exam used by Anísio Teixeira National Institute for Educational Students and research (Inep) to calculate the Ideb. The results point to the potential of mathematical modeling to approach curriculum contents proposed by the PCN, and indicate student learning, particularly, in the early years of elementary school.

Keywords: mathematics education; early years; mathematical modeling; Brazil Test; Ideb; Observatory of Education.

\section{Introdução}

As preocupações com relação à educação escolar têm orientado diferentes ações visando incrementar a formação dos estudantes, tanto em disciplinas específicas quanto em cidadania. A elaboração e distribuição de diversos documentos oficiais - como os Parâmetros Curriculares Nacionais (PCN) -, a organização do Sistema de Avaliação da Educação Básica (Saeb) e a realização da Prova Brasil são algumas dessas ações.

Além disso, diversos programas têm sido desenvolvidos por instituições de ensino superior e programas de pós-graduação em prol da educação básica, como o Programa Observatório da Educação, gerenciado pela Coordenação de Aperfeiçoamento de Pessoal de Nível Superior (Capes), em parceria com o Instituto Nacional de Estudos e Pesquisas Educacionais Anísio Teixeira (Inep). Este programa tem por objetivo proporcionar a articulação entre pós-graduação, licenciaturas e escolas de educação básica e estimular a produção acadêmica e a formação de recursos para pós-graduação, em nível de mestrado e doutorado.

Neste artigo, olhamos para um projeto, em desenvolvimento, no âmbito do Programa Observatório da Educação - com vigência de 2011 a 2014 -, que tem como foco o ensino e a aprendizagem de Matemática na esfera dos anos iniciais do ensino fundamental e, mediante suas 
Reflexões a respeito do uso da modelagem matemática em aulas nos anos

ações, vislumbra a elevação do Índice de Desenvolvimento da Educação Básica (Ideb) da escola cujos professores e alunos constituem objeto de pesquisa. Discutimos, em particular, as implicações, para uma turma de estudantes, de uma investigação que representa um dos braços desse projeto e constitui parte de uma pesquisa de mestrado realizada nos anos de 2011 e 2012. Seu desenvolvimento tem como cerne o uso da modelagem matemática em sala de aula e sua potencialidade para o estudo de conteúdos e apropriação de conceitos matemáticos.

Este texto é resultado de uma inquietação que nos surgiu diante dos objetivos, relativos ao Ideb, que se pretendem alcançar a partir das ações desenvolvidas com alunos e professores da escola. No momento da investigação, realizada em 2012, os estudantes estavam no $5^{\circ}$ ano do ensino fundamental e, ao participarem da pesquisa de mestrado em 2011, no $4^{\circ}$ ano, desenvolveram atividades de modelagem matemática. Nesse contexto, buscamos investigar como seria o desempenho desses alunos ao resolverem questões da Prova Brasil, um dos instrumentos utilizados pelo Inep na avaliação da escola e no cálculo do Ideb. Para isso, propomos aos estudantes 15 questões disponibilizadas pelo Inep, ${ }^{1}$ em seu portal, como modelos da Prova Brasil. As questões contemplam conteúdos abordados nas atividades de modelagem matemática desenvolvidas pelos estudantes. A análise e a discussão dos resultados são apresentadas neste artigo.

A estrutura do texto envolve apresentação do Programa Observatório da Educação e do projeto desenvolvido; abordagem a respeito do que é modelagem matemática na Educação Matemática e de como fazer modelagem em sala de aula; descrição de algumas atividades desenvolvidas pelos estudantes, incluindo os modelos matemáticos produzidos; caracterização do Ideb, da Prova Brasil e das questões propostas aos estudantes; e discussão quanto ao desempenho dos estudantes nessas questões e em relação ao potencial da modelagem matemática na sala de aula nos anos iniciais do ensino fundamental.

\section{O Programa Observatório da Educação}

O Programa Observatório da Educação (Obeduc) foi instituído pelo Decreto Presidencial no 5.803, de 8 de junho de 2006, em decorrência da parceria entre a Capes e o Inep, na perspectiva de fortalecer o diálogo entre pós-graduação, licenciaturas e escolas de educação básica e estimular o desenvolvimento de pesquisas que tenham o ensino como eixo de investigação.

O intuito do programa é estreitar a relação entre a comunidade

${ }^{1}$ O Inep disponibiliza na "Área de documentos da Prova Brasil e Saeb", em seu site, modelos de questões e provas, em formato pdf, que podem ser visualizados no endereço: < http://provabrasil. inep.gov.br/downloads $>$. acadêmica, os gestores das políticas nacionais de educação e os diversos atores envolvidos no processo educacional, por meio da disseminação de dados estatísticos educacionais produzidos pelo Inep - por exemplo, o Ideb - como subsídio ao aprofundamento de estudos sobre a realidade educacional brasileira. 
Nesse sentido, o programa visa envolver escolas, como a que apresentamos a seguir, em projetos de pesquisa e extensão, numa atitude que almeja a melhoria na qualidade do ensino e da aprendizagem, de modo a apresentar melhores resultados nas avaliações educacionais.

\section{A escola}

A escola, a que nos referimos, está localizada no norte do Estado do Paraná. Foi criada em 20 de outubro de 1997, por meio do Decreto $n^{\circ}$ 189/97. Trata-se de uma escola pública e municipal, cujo sistema de ensino é integral, sendo destinado apenas aos anos iniciais do ensino fundamental.

No ano de 2011, possuía 155 estudantes, os quais estavam organizados em seis turmas: duas de $2^{\circ}$ ano, duas de $3^{\circ}$ ano, uma de $4^{\circ}$ ano e uma de $4^{\mathrm{a}}$ série.

É uma escola relativamente nova e tem empreendido esforços para melhorias no ensino e na aprendizagem também na expectativa de obter melhores resultados no Ideb, ${ }^{2}$ cujas avaliações e metas constam na Tabela 1.

Tabela 1 - Notas Observadas e Metas Projetadas para o Ideb da Escola

\begin{tabular}{|c|c|c|c|c|c|c|}
\hline \multicolumn{2}{|c|}{ Ideb Observado } & \multicolumn{5}{|c|}{ Metas Projetadas } \\
\hline $\mathbf{2 0 0 7}$ & $\mathbf{2 0 0 9}$ & $\mathbf{2 0 0 7}$ & $\mathbf{2 0 0 9}$ & $\mathbf{2 0 1 1}$ & $\mathbf{2 0 1 3}$ & $\mathbf{2 0 1 5}$ \\
\hline 5.0 & 4.9 & - & 5.2 & 5.5 & 5.8 & 6.0 \\
\hline
\end{tabular}

Fonte: Inep

A partir das informações da Tabela 1, disponibilizadas pelo Inep, notamos que em 2009 o Ideb dessa escola diminuiu de 5.0 para 4.9, quando a nota esperada era de 5.2. Tal resultado indica uma lacuna na formação, de modo particular, no que se refere às disciplinas de Língua Portuguesa e de Matemática, avaliadas na Prova Brasil.

No que tange à esfera da educação matemática, um programa de pós-graduação, de uma universidade estadual também do norte do Paraná, na intenção de colaborar para o preenchimento dessa lacuna, elaborou um projeto de pesquisa envolvendo professores e estudantes dessa escola, bem como alunos de mestrado, doutorado e da licenciatura em Matemática, cujo tema visa contemplar a "Educação Matemática de professores que ensinam Matemática"; o projeto foi submetido ao Programa Observatório da Educação e entrou em vigor no ano de 2011. Na sequência, apresentamos algumas características desse projeto.

\section{O projeto Observatório na Escola}

O projeto "Educação Matemática de professores que ensinam Matemática" centra-se em dois eixos principais: formação continuada
${ }^{2}$ O Ideb das escolas pode ser consultado no seguinte endereço: $<$ http://ideb.inep.gov.br/>. 
e educação básica. Tem por objetivo fomentar a produção acadêmica relativa à formação de professores que ensinam Matemática e à formação de recursos humanos em Educação Matemática na educação básica, na graduação e na pós-graduação (mestrado e doutorado). Trata-se de um projeto de intervenção que, entre seus objetivos, busca contribuir para a elevação do Ideb da escola.

Os encontros, realizados semanalmente na escola, têm duração de três horas e abarcam a participação de estudantes de mestrado, doutorado e licenciatura em Matemática e de professoras da instituição de ensino.

Neste texto, focamo-nos na investigação dirigida por um estudante de mestrado participante do projeto e que foi realizada na turma de $4^{\circ}$ ano da escola, cujos alunos desenvolveram atividades de modelagem matemática, sendo esta utilizada como uma alternativa pedagógica para o ensino e aprendizagem de Matemática, conforme sugere Almeida e Dias (2004).

\section{O observatório na sala de aula}

A turma de $4^{\circ}$ ano cujos alunos desenvolveram as atividades de modelagem matemática possuía 36 estudantes, com idades que variavam entre 8 e 9 anos. Era uma turma numerosa, mas com alunos participativos e comprometidos com as atividades que lhes eram propostas. Foi a primeira vez que esses estudantes tiveram contato com a modelagem matemática.

O desenvolvimento de atividades de modelagem matemática em sala de aula tem sido amplamente difundido na literatura, como aponta a pesquisa de Silveira (2007) e o trabalho de Blum e Borromeo Ferri (2009), contudo, poucos são os trabalhos publicados que as contemplam nos anos iniciais do ensino fundamental, conforme colocam Luna e Alves (2007) e Dias e Chaves (2009). Entre as muitas possibilidades, este trabalho se configura como um exemplo do uso da modelagem nesse nível de escolaridade.

Entretanto, faz-se necessário esclarecer como esta investigação, associada à modelagem matemática, situa-se no projeto "Educação Matemática de professores que ensinam Matemática". Para isso, discutimos a seguir os dois principais objetivos do projeto que esta investigação se propõe a cumprir.

1) Fomentar, disseminar e desenvolver metodologias de prática de ensino significativas, para enfrentamento dos problemas na área de Matemática.

Em resposta a esse objetivo, propomos a modelagem matemática como alternativa para as aulas dessa disciplina e que prima por uma abordagem mais integrada dos conteúdos, permitindo que os estudantes, na busca por um modelo adequado a uma determinada situação, lidem com problemas que os aproximam da realidade, buscando na Matemática subsídios para solucioná-los e, ao mesmo tempo, promover a aprendizagem dessa disciplina. 
2) Investigar contextos em que os participantes desenvolvam sua capacidade para analisar, explicar seu raciocínio e comunicar suas ideias matemáticas enquanto propõem, formulam, resolvem e interpretam problemas em uma variedade de situações.

Nesse caso, propomos aos participantes envolvidos, os estudantes do $4^{\circ}$ ano, o desenvolvimento de atividades de modelagem matemática, os quais, organizados em grupos, tiveram a oportunidade de discutir suas ideias e explicar o raciocínio utilizado na produção dos modelos matemáticos, em uma diversidade de situações, contemplando temas como anéis, área dos estudantes na sala de aula, energia elétrica, beleza de uma pessoa, caixa d'água, câmbio dólar-real e flúor.

\section{Modelagem matemática na Educação Matemática}

A modelagem matemática configura-se como uma possibilidade de atividades para as aulas, a qual, visando à aprendizagem dos alunos, lhes proporciona conhecer aplicações da Matemática e contribui para a consolidação de uma imagem desta disciplina como ciência que faz parte da história e da cultura humana e possibilita a construção ou produção de conhecimento, refletindo no desenvolvimento de outros aspectos - como apontam Klüber e Burak (2009, p. 3), quando afirmam que "a relação estabelecida com o objeto matemático visa à aplicação ou à produção de conhecimento matemático. Nessa perspectiva, ocorrem aprendizagens, interações e criatividade".

Em termos gerais, a dinâmica das aulas com modelagem matemática pode fortalecer o desenvolvimento de múltiplos aspectos favoráveis à aprendizagem, incluindo-se a autonomia na resolução de problemas matemáticos característicos da realidade e a apreciação crítica do uso da Matemática nessas situações, o que se reflete na atuação do sujeito na sociedade. Além disso, a modelagem contribui para o desenvolvimento de competências matemáticas, desencadeando a retenção de tópicos matemáticos e, como consequência, a construção do conhecimento na área.

\section{O que é modelagem matemática e modelo matemático}

Para o desenvolvimento de atividades, escolha dos temas e formulação dos problemas, baseamo-nos, essencialmente, na concepção de Almeida e Brito (2005), que concebem a modelagem matemática como uma alternativa pedagógica na qual fazemos uma abordagem, por meio da matemática de uma situação não essencialmente matemática.

Com base em Almeida (2010), podemos descrever, de modo geral, o processo envolvido no desenvolvimento de uma atividade de modelagem matemática da seguinte forma: um problema, que constitui a situação inicial, um modelo matemático, que representa uma solução para o 
problema e caracteriza a situação final, e uma série de procedimentos, necessários para que haja a passagem da situação inicial para a final. Entre esses procedimentos, podemos elencar a coleta de dados e informações, a definição de variáveis, a formulação de hipóteses, a realização de simplificações, as transições entre a linguagem natural do fenômeno e a linguagem matemática, a obtenção e validação de um modelo matemático e a comunicação dos resultados obtidos na investigação.

De acordo com D'Ambrósio (2009, p. 91, tradução nossa), "a prática de criar modelos e operar com eles utiliza instrumentos materiais e intelectuais. No caso da utilização de instrumentos matemáticos, referimonos a essa prática como modelagem matemática".

Segundo Lesh (2010, p. 18, tradução nossa), "um modelo é um sistema para descrever ou projetar algum outro sistema com algum propósito específico". Nessa perspectiva, um modelo serve para representar ou tornar presente o objeto matemático, podendo, portanto, assumir diversas representações, por exemplo, tabela, gráfico, figura, expressão algébrica, descrição em linguagem natural ou conjunto de contas e expressões numéricas, entre outras.

Todavia, o modelo matemático não tem um fim em si só, mas a sua construção, ao mesmo tempo que contribui para a resolução de um problema, também viabiliza a sistematização do conteúdo matemático que emerge dessa construção. Nesse sentido, a obtenção de um modelo não é o objetivo último de uma atividade de modelagem matemática, mais importante do que o modelo obtido é o processo utilizado, a análise crítica e sua inserção no contexto sociocultural. Bassanezi (2004, p. 38) afirma que "o fenômeno modelado deve servir de pano de fundo ou motivação para o aprendizado das técnicas e conteúdos da própria Matemática".

\section{Como fazer modelagem matemática?}

Por mais que possamos observar uma diversidade de trabalhos na literatura que apontam para resultados positivos no que se refere ao uso da modelagem matemática em sala de aula (Almeida; Dias, 2004, Almeida; Silva; Vertuan, 2012, Barbosa, 2001, Blum, 2011, Borromeo Ferri, 2010, D’Ambrósio, 2009, Doerr; Lesh, 2011, Rosa; Orey, 2012), o fazer modelagem ainda incomoda, de certo modo, professores, estudantes e pesquisadores, pois exige desses atores uma mudança de atitude no cenário da sala de aula.

Nesse contexto, remetemo-nos a um desses agentes, o aluno, abordando a seguinte questão: Como fazer com que estudantes, não habituados com ambientes de problematização e investigação característicos da modelagem matemática, como pressupõe Barbosa (2004) -, se familiarizem com atividades desse caráter?

Referimo-nos, portanto, com base em Almeida, Silva e Vertuan (2012), ao que denominamos "familiarização dos alunos" com a modelagem matemática, indicando que esta pode se dar por meio de três momentos. 
Em um primeiro momento, o professor propõe aos alunos um tema para estudo. Acerca desse tema, ele aponta um problema, o qual deve ser investigado pelos estudantes. Os dados e informações necessários para solucioná-lo são fornecidos, neste momento, pelo professor, cabendo aos alunos a análise dessas informações, a realização de simplificações, a definição de hipóteses e variáveis, a transição da linguagem natural do fenômeno para uma linguagem matemática e a obtenção e validação de um modelo matemático que representa uma resposta para o problema proposto inicialmente.

Em um segundo momento, o professor escolhe um tema e apresenta um problema a ser investigado pelos estudantes, cabe a eles complementar ou realizar a coleta de dados e analisar as informações necessárias para a solução da questão. Neste momento, os alunos são mais responsáveis pela condução e produção do modelo matemático, bem como de sua avaliação e interpretação, sendo suas ações avaliadas pelo professor.

Em um terceiro momento, o docente fornece aos estudantes um espaço para a condução das atividades de modelagem. Organizados em grupos, eles podem optar por um tema e identificar um problema a ser investigado. Sob a orientação do professor, os alunos são responsáveis por todas as ações requeridas para o desenvolvimento de uma atividade de modelagem matemática, desde a coleta de dados e informações, a definição de hipóteses e variáveis, as simplificações e a transição entre linguagens, até a produção de um modelo matemático capaz de representar uma resposta para a situação-problema inicialmente proposta. Cabe também a eles a comunicação dos resultados à comunidade escolar, seja sob a forma de apresentações, seminários, ou de redação de textos e artigos, estimulando a discussão acerca do estudo desenvolvido.

"Na medida em que o aluno vai realizando as atividades nos 'diferentes momentos' [...], a sua compreensão acerca do processo de modelagem, da resolução dos problemas em estudo e da reflexão sobre as soluções encontradas vai se consolidando" (Almeida; Dias, 2004, p. 26).

\section{A modelagem na sala de aula}

Com base nos pressupostos teóricos apresentados, optamos por propor aos estudantes do $4^{\circ}$ ano o desenvolvimento de atividades de modelagem matemática segundo os três momentos a que nos referimos. Assim, foram desenvolvidas duas atividades do primeiro momento, duas do segundo e três do terceiro, totalizando sete atividades.

Para o desenvolvimento dessas atividades, os estudantes estavam organizados em grupos com 3 a 6 componentes, dependendo da atividade. As aulas foram gravadas em áudio e em vídeo a fim de coletar dados para a pesquisa, todavia, as principais fontes de informações foram os registros produzidos pelos estudantes e as anotações feitas pelo pesquisador.

Com o objetivo de preservar a identidade dos alunos, ao apresentar os resultados do desenvolvimento das atividades, enumeramo-los de 
1 a 36, a partir de uma lista em que os nomes foram organizados em ordem alfabética. As características das atividades desenvolvidas são apresentadas no Quadro 1.

\section{Quadro 1 - Atividades de Modelagem Desenvolvidas pelos Estudantes do $4^{\circ}$ Ano}

\begin{tabular}{|c|c|c|}
\hline Momento & Problemática & Materiais disponíveis \\
\hline \multirow[t]{2}{*}{$1^{\circ}$ momento } & $\begin{array}{l}\text { Como se determina o tamanho de } \\
\text { um anel? }\end{array}$ & $\begin{array}{l}\text { Folha com informações, régua, fecho de } \\
\text { arame revestido com plástico e papéis } \\
\text { para anotação. }\end{array}$ \\
\hline & $\begin{array}{l}\text { Quantos alunos cabem na sua sala } \\
\text { de aula? }\end{array}$ & $\begin{array}{l}\text { Folha com informações, fita métrica, } \\
\text { trena e papéis para anotação. }\end{array}$ \\
\hline \multirow{2}{*}{$2^{\circ}$ momento } & $\begin{array}{l}\text { Quanto você gasta com energia } \\
\text { elétrica para assistir o seu desenho } \\
\text { favorito? E para tomar banho? }\end{array}$ & $\begin{array}{l}\text { Folha com informações, fatura de } \\
\text { energia elétrica, calculadora e papéis } \\
\text { para anotação. }\end{array}$ \\
\hline & $\begin{array}{l}\text { Será que é possível medir a beleza } \\
\text { de uma pessoa? }\end{array}$ & $\begin{array}{l}\text { Folha com informações, fita métrica, } \\
\text { calculadora e papéis para anotação. }\end{array}$ \\
\hline \multirow{3}{*}{$3^{\circ}$ momento } & $\begin{array}{l}\text { Como se determina o valor, em } \\
\text { reais, de uma quantia em dólar? }\end{array}$ & $\begin{array}{l}\text { Computador, internet, folhas para } \\
\text { anotação e cartolina para a confecção } \\
\text { de um cartaz com os resultados da } \\
\text { investigação. }\end{array}$ \\
\hline & Qual caixa d'água comprar? & $\begin{array}{l}\text { Computador, internet, folhas para } \\
\text { anotação e cartolina para a confecção } \\
\text { de um cartaz com os resultados da } \\
\text { investigação. }\end{array}$ \\
\hline & $\begin{array}{l}\text { Quanto é gasto com flúor na } \\
\text { escola? }\end{array}$ & $\begin{array}{l}\text { Computador, internet, folhas para } \\
\text { anotação e cartolina para a confecção } \\
\text { de um cartaz com os resultados da } \\
\text { investigação. }\end{array}$ \\
\hline
\end{tabular}

As atividades de modelagem matemática desenvolvidas resultaram na produção de diferentes modelos matemáticos, e com eles diversos conteúdos matemáticos foram contemplados. Entre essas atividades, descrevemos sucintamente o desenvolvimento de três delas para ilustrar o processo de modelagem matemática.

\section{Atividade do Primeiro Momento: Área dos Estudantes na Sala de Aula}

Refere-se ao primeiro momento de inserção de atividades de modelagem matemática em sala de aula, e, para o seu desenvolvimento, a turma foi organizada em grupos com 4 ou 5 estudantes - cada um recebeu uma folha com informações a respeito do tema e com o problema a ser investigado, como mostra a Figura 1. 


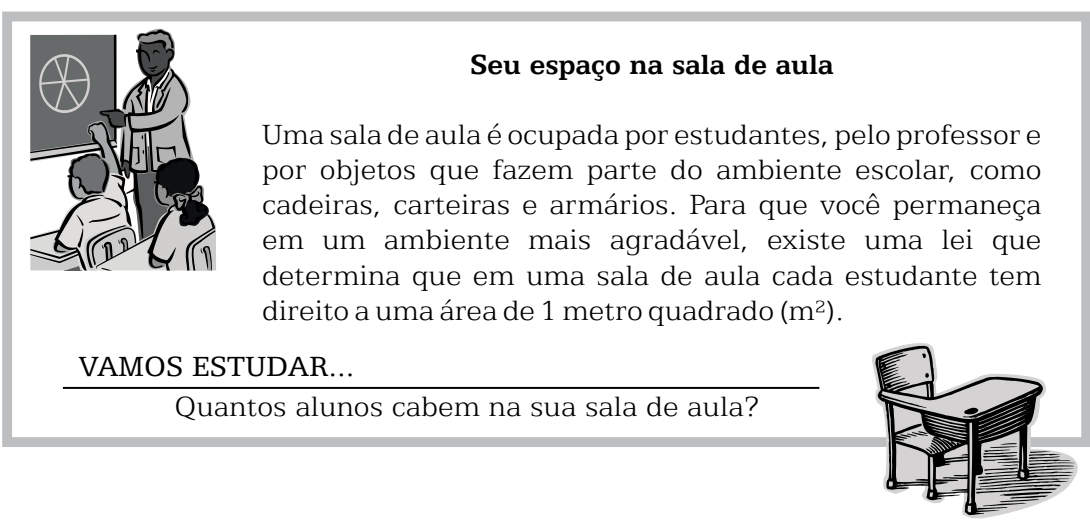

Figura 1 - Informações a respeito da Atividade "Área dos Estudantes na Sala de Aula"

Para a solução do problema, o professor explicou aos estudantes o que era "metro quadrado", exemplificando o seu espaço com um papelão na forma quadrangular. Na sequência, os alunos mediram a sala de aula com trenas e fitas métricas, desconsiderando os espaços de armários e bebedouro e reservando uma área para o professor (Figura 2).

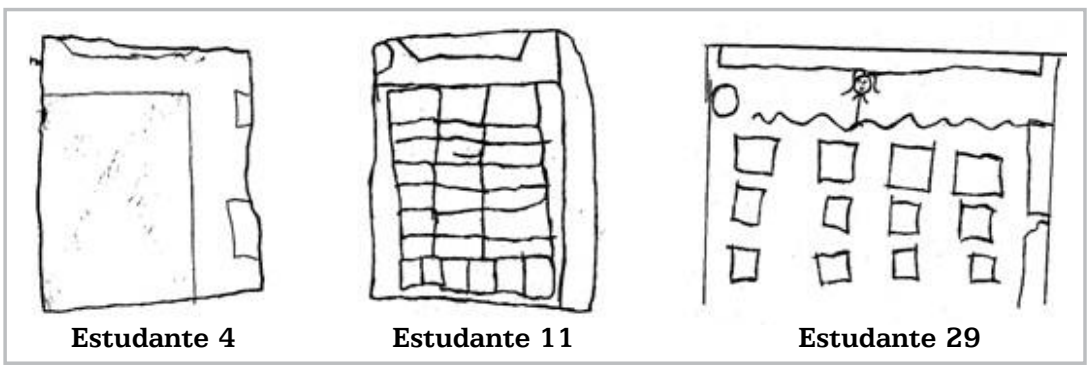

Figura 2 - Representações do Espaço Destinado aos Estudantes na Sala de Aula

Realizadas as medidas, os estudantes calcularam a área destinada a eles e, a partir da informação de que cada aluno tem direito a uma área de 1 metro quadrado, facilmente obtiveram uma resposta para o problema.

Em algumas situações, os estudantes tiveram que rever seus cálculos e medidas, uma vez que o resultado foi inferior ao número de alunos da sala ou mesmo porque desconsideraram a parte decimal das medidas. $\mathrm{O}$ professor auxiliou na revisão dos cálculos e das medidas, de modo que um novo resultado, mais condizente com a situação-problema, fosse encontrado (Figura 3).

Entre os conteúdos abordados nessa atividade está o cálculo de áreas retangulares e, por conseguinte, a multiplicação. Além disso, os estudantes se depararam com algumas medidas que não eram números inteiros, conduzindo à realização de operações de adição, subtração e multiplicação com números decimais. 


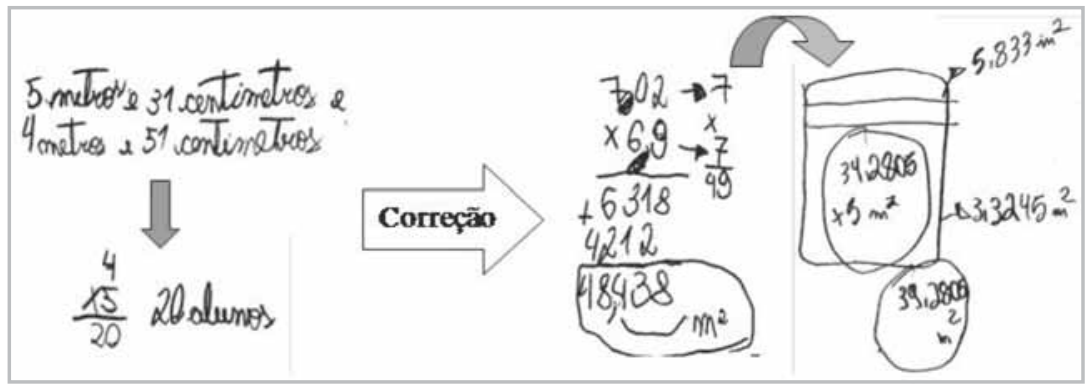

Figura 3 - Revisão dos Cálculos - Estudante 22

Os modelos matemáticos obtidos para essa situação consistem em representações numéricas e figurais, além da representação em linguagem natural. Na Figura 4, podemos observar alguns exemplos de modelos construídos pelos alunos.

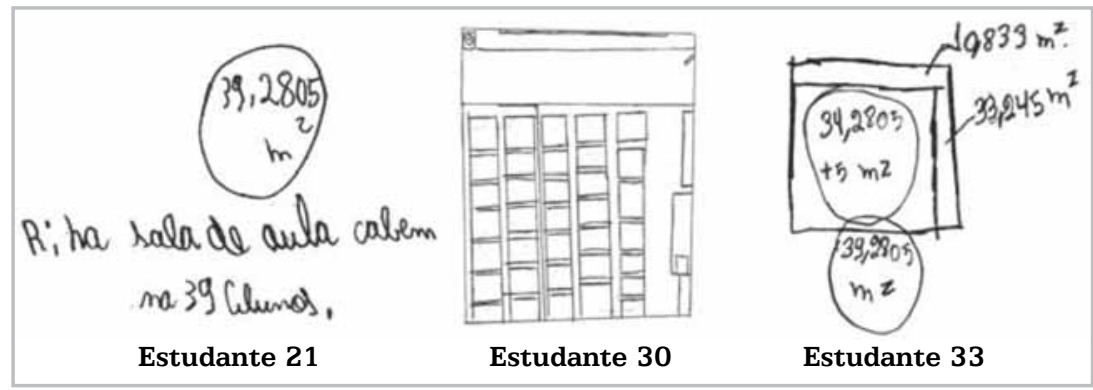

Figura 4 - Modelos Matemáticos para a Situação "Área dos estudantes na Sala de Aula"

\section{Atividade do Segundo Momento: Quanto é Gasto com Energia Elétrica?}

Refere-se ao segundo momento de inserção de atividades de modelagem matemática em sala de aula. Para o seu desenvolvimento, os estudantes foram organizados em oito grupos. O problema proposto e as informações disponibilizadas aos alunos podem ser visualizados na Figura 5.

Além das informações apresentadas na Figura 5, os estudantes puderam consultar a fatura de energia elétrica de suas casas, a fim de verificar o valor da tarifa por kWh que é cobrado em sua residência. Também disponibilizamos calculadoras aos estudantes, devido à complexidade dos números que apresentavam vários algarismos após a vírgula. Todavia, o professor auxiliou a turma na realização dos cálculos.

Nesse caso, para obter a solução do problema, os estudantes necessitavam apenas multiplicar o tempo de uso do aparelho, seja da televisão ou do chuveiro, em minutos, pelo consumo de energia elétrica do aparelho por minuto, em kWh - também disponibilizado aos estudantes, com base no site da Companhia Paranaense de Energia (Copel) -, e, por fim, pela tarifa da residência. Esse cálculo pode ser observado nas Figuras 6 e 7. 
Todo mês chega a nossa casa uma fatura que mostra os nossos gastos com energia elétrica. O valor cobrado depende de duas coisas:

- Quantidade de energia elétrica utilizada no mês, medida em quilowatts-hora (kWh);

- Valor da tarifa por kWh, determinada pela Companhia de Energia Elétrica de acordo com cada região.

Esses dados podem ser encontrados em sua fatura de energia elétrica.

QUANTA ENERGIA ELÉTRICA É GASTA EM SUA CASA? E QUANTO SE PAGA POR ISSO?

\section{VAMOS ESTUDAR..}

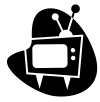

Qual é o seu desenho favorito? Quanta energia elétrica Docê gasta para assistir esse desenho? Quanto é pago por isso? Quanto tempo você gasta para tomar banho?

Q. Quanta energia elétrica você gasta? Quanto é pago por isso?

Figura 5 - Informações a respeito da Atividade "Quanto é Gasto com Energia Elétrica?"

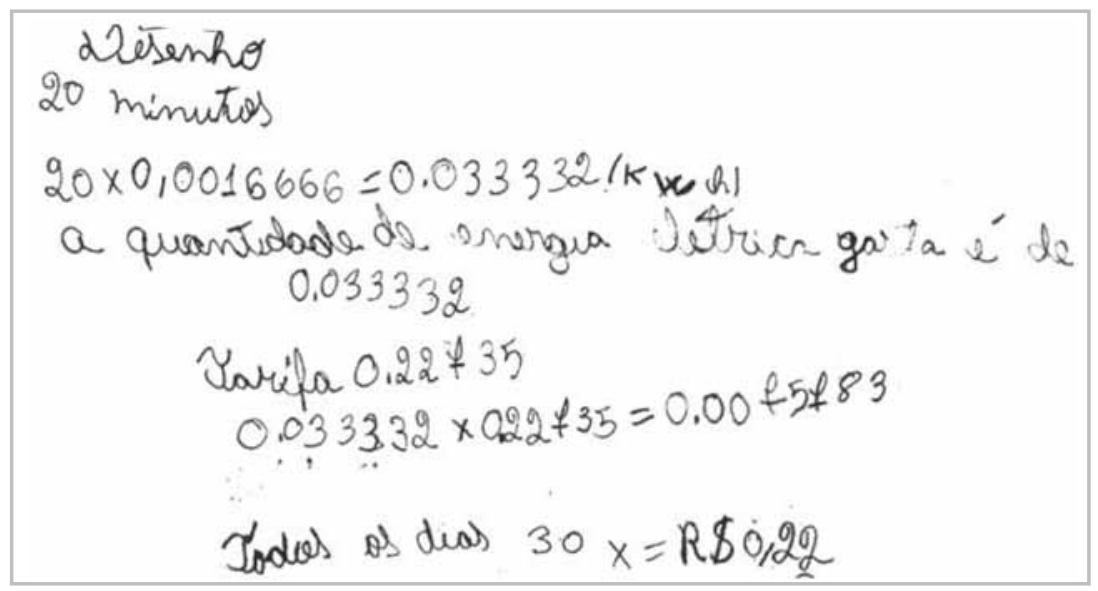

Figura 6 - Cálculo do Valor a Ser Pago de acordo com o Consumo da Televisão

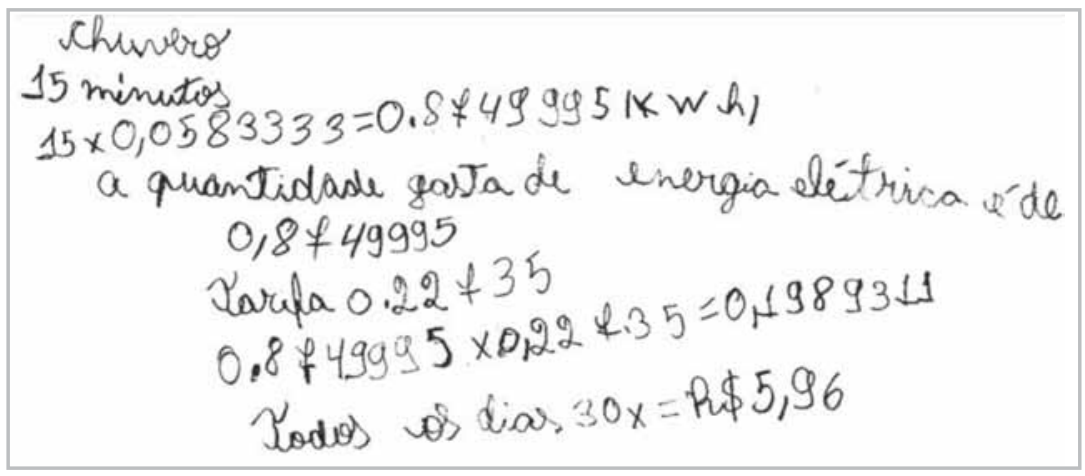

Figura 7 - Cálculo do Valor a Ser Pago de acordo com o Consumo do Chuveiro 
Nesta atividade, o modelo matemático para a situação consiste na representação dos alunos para especificar os gastos de cada eletrodoméstico. O modelo é procedimental e faz uso de uma linguagem essencialmente numérica.

Entre os conteúdos abordados, a multiplicação de números decimais fica evidente. Além disso, esta atividade contribuiu para o desenvolvimento do senso crítico e exploratório nos estudantes, mostrando a importância de conhecer e analisar a fatura de energia elétrica que eles recebem mensalmente em suas casas.

\section{Atividade do Terceiro Momento: Qual Caixa d'Água comprar?}

Esta situação-problema é resultado do terceiro momento de inserção de atividades de modelagem matemática em sala de aula, o que significa que seu desenvolvimento foi conduzido pelo grupo de oito estudantes que optou pelo estudo desse problema.

O tema surgiu a partir do interesse do grupo em pesquisar a respeito da água, mas, ao deparar-se com algumas informações acerca de caixas d'água, os estudantes se interessaram pela investigação de como a capacidade de uma caixa d'água pode ser determinada. As informações foram pesquisadas na internet, no laboratório de informática da escola.

Diante da situação exposta pelo estudante 25, de que sua família estava prestes a comprar uma caixa d'água para sua residência, o grupo formulou o seguinte problema: Como determinar a capacidade da caixa d'água necessária para a sua casa? Ou, nas palavras do estudante 3 (Figura 8),

$$
\text { Wuantos litros de agua presscisa ter sa caveca de água da minha casa? }
$$

Figura 8 - Problema Investigado pelo Grupo na Atividade "Qual Caixa d'Água Comprar?" - Estudante 3

Para a resolução do problema, eles buscaram identificar quais as capacidades de caixas d'água disponíveis para compra no mercado e informações que auxiliassem nesse cálculo. Os principais dados utilizados para a solução do problema podem ser visualizados na Figura 9.

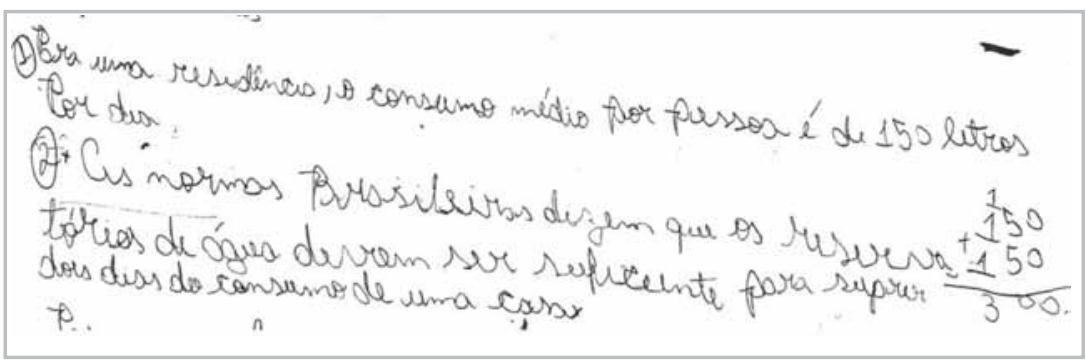

Figura 9 - Informações Encontradas pelos Alunos - Estudante 25 
Com essas informações, os estudantes conseguiram determinar uma estratégia para responder ao problema, resultando no modelo matemático para a situação (Figura 10). Este, apresentado basicamente por uma linguagem numérica, quase sempre vinha acompanhado de uma análise crítica em relação à resposta do problema, sob a forma de linguagem natural.

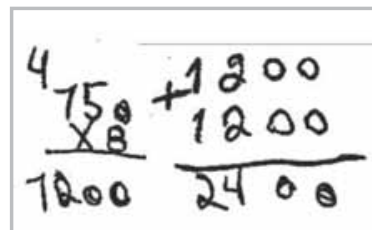

Estudante 12

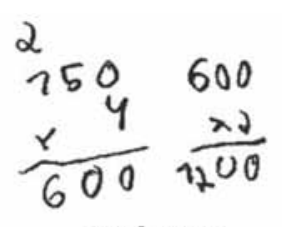

Estudante 16

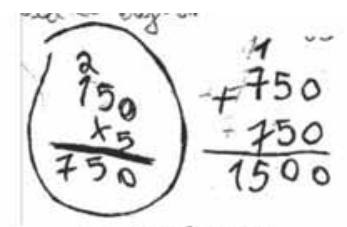

Estudante 23

\section{tenha que comprar a de 1.500 parque} năo se sende de 1,200.

Estudante 30

Figura 10 - Modelos Matemáticos para a Situação "Qual Caixa d'Água Comprar?"

Os modelos obtidos para essa situação também são procedimentais, pois indicam o que os estudantes precisam fazer para chegar ao resultado. Esses modelos, além de envolver os conceitos de adição, multiplicação e comparação, contribuíram para o desenvolvimento da ideia de função linear. Nesse contexto, os modelos matemáticos foram constituídos a partir do uso de linguagem natural e numérica.

\section{O Ideb, a Prova Brasil e um episódio com os estudantes}

O Índice de Desenvolvimento da Educação Básica (Ideb) foi calculado pela primeira vez em 2007, como resultado de um esforço em medir a qualidade do ensino nas escolas do País. É calculado com base no desempenho do estudante em avaliações do Inep ${ }^{3}$ - como a Prova Brasil e o Saeb - e em taxas de aprovação. Nesse sentido, a avaliação repousa sobre três aspectos: é preciso que o estudante aprenda, não repita o ano escolar e frequente a sala de aula. O Ideb é medido a cada dois anos e seu resultado é apresentado em uma escala de 0 a 10 . Tem como meta que as escolas municipais e estaduais obtenham, até o ano de 2022, a nota 6, que, segundo o Inep, corresponde à qualidade do ensino em países desenvolvidos.

A Prova Brasil, assim como o Saeb, são avaliações para diagnóstico, em larga escala, desenvolvidas pelo Inep em parceria com o Ministério da Educação (MEC). De acordo com esses órgãos governamentais, elas têm o objetivo de avaliar a qualidade do ensino oferecido pelo sistema educacional brasileiro a partir de testes padronizados e questionários socioeconômicos. Com base nos resultados e nas informações obtidas
${ }^{3}$ Os dados utilizados na produção deste texto estão disponíveis no portal do Inep: < http://portal. inep.gov.br/ $>$. 
por meio desses sistemas de avaliações, os órgãos responsáveis pela educação podem definir ações voltadas para o aprimoramento da qualidade da educação no País, contribuindo para a redução das debilidades identificadas, no que se refere aos recursos técnicos e financeiros.

O último resultado do Ideb, correspondente a 2011, foi divulgado pelo Inep em 14 de agosto de 2012 e indica que a escola a que nos referimos neste texto aumentou seu índice de 4.9 para 5.9, superando as metas de 2009, 2011 e 2013. O bom desempenho da escola nos levou a investigar como seria o desempenho na Prova Brasil dos estudantes que participaram das atividades de modelagem matemática desenvolvidas durante o ano de 2011.

Nessa perspectiva, propomos 15 questões, associadas à Prova Brasil, aos estudantes, agora no $5^{\circ}$ ano do ensino fundamental, com o intuito de verificar o seu desempenho ao serem avaliados com questões elaboradas por órgãos governamentais, como o Inep e o MEC.

\section{As questões}

As questões selecionadas fazem parte das amostras fornecidas pelo Inep em seu portal, e o critério para escolha foi a coincidência de conteúdos entre a questão e algumas das atividades de modelagem desenvolvidas durante o ano de 2011. As questões propostas aos estudantes são apresentadas no Quadro 2.

Quadro 2 - Questões Associadas à Prova Brasil Propostas aos Estudantes

1) A turma de Joana resolveu fazer uma pesquisa sobre o tipo de filme que as crianças mais gostavam. Cada criança podia votar em um só tipo de filme. A tabela abaixo mostra o resultado da pesquisa com as meninas e com os meninos:

\begin{tabular}{|l|c|c|}
\hline \multirow{2}{*}{\multicolumn{1}{|c|}{ Tipo de filme }} & \multicolumn{2}{|c|}{ Número de votos } \\
\cline { 2 - 3 } & Meninas & Meninos \\
\hline Aventura & 8 & 10 \\
\hline Comédia & 7 & 2 \\
\hline Desenho animado & 5 & 5 \\
\hline Terror & 2 & 4 \\
\hline
\end{tabular}

Qual o tipo de filme preferido pelos MENINOS?
(A) Aventura
(B) Comédia
(C) Desenho animado
(D) Terror 
2) Um fazendeiro tinha 285 bois. Comprou mais 176 bois e depois vendeu 85 deles. Quantos bois esse fazendeiro tem agora?
(A) 266
(B) 376
(C) 476
(D) 486

3) Uma merendeira preparou 558 pães que foram distribuídos igualmente em 18 cestas. Quantos pães foram colocados em cada cesta?
(A) 31
(B) 310
(C) 554
(D) 783

4) Gilda comprou copos descartáveis de 200 mililitros, para servir refrigerantes em sua festa de aniversário. Quantos copos ela encherá com 1 litro de refrigerante?
(A) 3
(B) 5
(C) 7
(D) 9

5) Faltam 31 dias para o aniversário de João. Quantas semanas completas faltam para o aniversário dele?
(A) 3
(B) 4
(C) 5
(D) 6

6) O número decimal correspondente ao ponto assinalado na reta numérica é
(A) 0,3
(B) 0,23
(C) 2,3
(D) 2,03

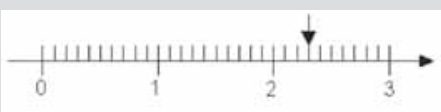

7) Vamos medir o parafuso?
(A) 2,1
(B) 2,2
(C) 2,3
(D) 2,5

O parafuso mede:

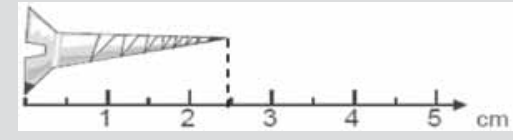

8) João participou de um campeonato de judô na categoria juvenil, pesando 45,350kg. Cinco meses depois estava $3,150 \mathrm{~kg}$ mais pesado e precisou mudar de categoria. Quanto ele estava pesando nesse período?
(A) $14,250 \mathrm{~kg}$
(B) $40,850 \mathrm{~kg}$
(C) $48,500 \mathrm{~kg}$
(D) $76,450 \mathrm{~kg}$ 
9) Uma professora da $4^{\mathrm{a}}$ série pediu que uma aluna marcasse numa linha do tempo o ano de 1940.

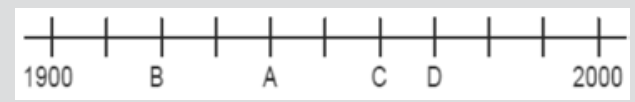

Que ponto a aluna deve marcar para acertar a tarefa pedida?
(A) $\mathrm{A}$
(B) $\mathrm{B}$
(C) $\mathrm{C}$
(D) $\mathrm{D}$

10) Em Belo Horizonte, ontem a temperatura máxima foi de 28,3 graus e, hoje, é de 26,7 graus. De quantos graus é a diferença entre as duas temperaturas?
(A) 1,4 grau
(B) 1,6 grau
(C) 2,4 graus
(D) 2,6 graus

11) Fernando tem, no seu cofrinho, cinco moedas de $R \$ 0,05$, oito moedas de $R \$ 0,10$ e três moedas de $R \$ 0,25$. Que quantia Fernando tem no cofrinho?
(A) $\mathrm{R} \$ 1,55$
(B) $\mathrm{R} \$ 1,80$
(C) $\mathrm{R} \$ 2,05$
(D) $\mathrm{R} \$ 4,05$

12) Ao usar uma régua de $20 \mathrm{~cm}$ para medir uma mesa, Henrique observou que ela cabia 27 vezes no comprimento da mesa. Ele multiplicou esses valores e encontrou $540 \mathrm{~cm}$. Em metros, o comprimento da mesa é de
(A) $0,54 \mathrm{~m}$
(B) $5,4 \mathrm{~m}$
(C) $54 \mathrm{~m}$
(D) $540 \mathrm{~m}$

13) $O$ carro de João consome 1 litro de gasolina a cada 10 quilômetros percorridos. Para ir da sua casa ao sítio, que fica distante 63 quilômetros, o carro consome
(A) 5,31 .
(B) 61 .
(C) 6,31 .
(D) $7 \mathrm{l}$.

14) Ricardo anda de bicicleta na praça perto de sua casa. Representada pela figura. Se ele der a volta completa na praça, andará:
(A) $160 \mathrm{~m}$
(B) $100 \mathrm{~m}$
(C) $80 \mathrm{~m}$
(D) $60 \mathrm{~m}$

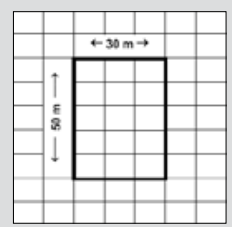

15) O piso de uma sala está sendo coberto por cerâmica quadrada. Já foram colocadas 7 cerâmicas, como mostra a figura. Quantas cerâmicas faltam para cobrir o piso?
(A) 6
(B) 7
(C) 8
(D) 15

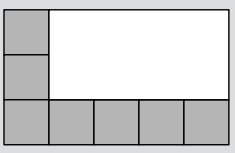


De modo geral, podemos observar aproximações entre as questões propostas aos estudantes e as atividades de modelagem matemática desenvolvidas por eles. Assim como Almeida (2010) propõe para as atividades de modelagem, as questões selecionadas apresentam como ponto de partida uma problemática, advinda de situações que, em certa medida, podem ser associadas à realidade; a partir dessa problemática, os estudantes deveriam encontrar, por meio de uma série de procedimentos, uma resposta que fosse adequada para a pergunta enunciada.

Contudo, enquanto nas questões associadas à Prova Brasil o foco está na resposta, isto é, na aplicação de conteúdos matemáticos, nas práticas de modelagem matemática, o foco está na produção e análise de um modelo matemático que permita a obtenção dessa resposta a partir de instrumentos matemáticos. Nesse sentido, ainda que se vislumbrem semelhanças entre os conteúdos matemáticos abordados por meio das atividades de modelagem e aqueles associados às questões cuja resolução propusemos aos alunos, a natureza das atividades é diferente.

\section{O desempenho dos estudantes na resolução das questões}

Dos 36 estudantes que participaram do desenvolvimento das atividades de modelagem matemática no ano anterior, 26 estavam presentes e realizaram a prova com as questões que selecionamos.

A correção da prova indica que os alunos apresentaram um bom desempenho ao resolverem as questões que lhes foram propostas, como pode ser observado na Tabela 2, na qual apresentamos o número de acertos e erros em cada questão. Além disso, apresentamos os conteúdos englobados em suas resoluções e que correspondem aos utilizados no desenvolvimento das atividades de modelagem matemática.

Ao observar a Tabela 2, constatamos que, em apenas 3 das 15 questões, o número de erros superou o de acertos. Na questão 7, que envolve números decimais associados à ideia de fração, notamos que muitos estudantes erraram essa questão ou marcaram 2,1 ou 2,3 como medida do parafuso - acreditamos que essa confusão foi gerada devido à falta dos demais traços dos milímetros na régua, por isso o 2,1, ou devido à medida do parafuso estar entre 2 e 3, por isso o 2,3. Na questão 9 , em que os estudantes necessitavam conciliar a ideia de divisão com a de medida; e na questão 12, que envolve a conversão entre unidades de comprimento, especificamente, de centímetro para metro.

Para as questões 6 e 10, o número de erros e o de acertos são próximos. Essas questões envolvem a identificação de um número decimal, a partir da régua, e a subtração entre números também desse conjunto.

As questões que mais apresentaram acertos foram: a questão 1, que foi resolvida corretamente por todos os alunos, envolve o conteúdo estruturante Tratamento da Informação, abrangendo a interpretação de dados em linguagem tabular; a questão 2, com 23 acertos, considerada relativamente simples, é solucionada a partir da realização de duas 
operações, uma de adição e outra de subtração, ambas envolvendo números naturais; a questão 3, com 22 acertos, contempla uma situação que é resolvida a partir de uma divisão exata entre números naturais; e as questões 8 e 11, ambas com 20 acertos, envolvem a adição de números decimais, além disso, a questão 11 também requer uma multiplicação entre esses números.

Tabela 2 - Desempenho dos Estudantes nas Questões com seus Respectivos Conteúdos

\begin{tabular}{|c|c|c|l|}
\hline Questão & $\mathbf{N}^{\mathbf{0}}$ de Acertos & $\mathbf{N}^{\mathbf{0}}$ de Erros & \multicolumn{1}{|c}{ Conteúdos } \\
\hline 1 & 26 & 0 & Interpretação de tabela \\
\hline 3 & 23 & 3 & Adição e subtração de números naturais \\
\hline 4 & 22 & 4 & Divisão exata de números naturais \\
\hline 5 & 14 & 12 & $\begin{array}{l}\text { Divisão exata de números naturais e conversão } \\
\text { de unidades de volume }\end{array}$ \\
\hline 6 & 15 & 11 & Divisão de números naturais com resto \\
\hline 8 & 13 & 13 & Números decimais na régua \\
\hline 9 & 10 & 16 & Números decimais como fração \\
\hline 10 & 20 & 6 & Adição de números decimais \\
\hline 11 & 12 & 14 & Divisão como medida \\
\hline 13 & 13 & 13 & Subtração de números decimais \\
\hline 14 & 20 & 6 & Adição e multiplicação de números decimais \\
\hline 15 & 11 & 15 & Conversão de unidades de comprimento \\
\hline
\end{tabular}

Nas demais questões, 4, 5, 13, 14 e 15, o número de acertos também foi maior que o de erros, algumas com uma diferença maior, como as questões 13 e 15, envolvendo uma divisão com resultado decimal e o cálculo de área, respectivamente, e outras com uma diferença menor, questões 4, 5 e 14, nas quais o conteúdo envolvido era divisão, conversão entre unidades de volume e perímetro.

No que concerne às atividades de modelagem, esses conceitos foram abordados durante várias delas. Vejamos alguns exemplos.

O primeiro contato dos estudantes com situações que envolvem o uso de números decimais foi com a primeira atividade de modelagem matemática desenvolvida por eles, com o tema "Tamanho de Anéis". Esse conceito emergiu também nas demais atividades, contemplando essa classe de números em suas várias dimensões, seja como medida (anéis, área dos estudantes na sala de aula, beleza, flúor), resultado de uma operação (área dos estudantes na sala de aula, energia elétrica, beleza, flúor), valor de uma constante (energia elétrica, beleza, dólar), quantia do sistema monetário (energia elétrica, dólar, caixa d'água, flúor), etc. Como consequência, as operações com números decimais foram abordadas em todas as atividades. 
As medidas também foram utilizadas nas atividades, seja com régua, fita métrica ou trena, os estudantes mediram o comprimento da circunferência de seus dedos e dos moldes de anéis e o comprimento e a largura da sala de aula - o perímetro, de forma implícita -, com o intuito de descobrir a área e as suas alturas, bem como as dos colegas, a fim de encontrar a proporção áurea.

As conversões foram úteis na atividade dos anéis, ao transformarem as medidas em milímetros para centímetros; na atividade da área, em centímetros para metros; e na atividade do flúor, em mililitros para litros.

Em linhas gerais, podemos inferir que o desempenho dos estudantes na avaliação foi satisfatório, sendo que a maioria, 19 entre os 26 que a realizaram, acertou mais do que a metade das questões, conforme mostra a Tabela 3.

Tabela 3 - Desempenho dos Estudantes na Avaliação

\begin{tabular}{|c|c|}
\hline $\mathbf{N}^{\mathbf{o}}$ de Acertos & Quantidade \\
\hline 0 & 0 \\
\hline 1 & 0 \\
\hline 2 & 0 \\
\hline 3 & 1 \\
\hline 4 & 2 \\
\hline 5 & 0 \\
\hline 6 & 1 \\
\hline 7 & 3 \\
\hline 8 & 3 \\
\hline 9 & 1 \\
\hline 10 & 1 \\
\hline 11 & 6 \\
\hline 12 & 4 \\
\hline 13 & 3 \\
\hline 14 & 1 \\
\hline 15 & 0 \\
\hline
\end{tabular}

Em termos de aprendizagem, tomamos como base o fato de que os estudantes foram capazes de utilizar o conhecimento construído em relação aos conteúdos abordados nas atividades de modelagem matemática em outras situações, como as propostas nas questões associadas à Prova Brasil, o que, segundo D'Amore (2007), sinaliza a aprendizagem.

Esses resultados nos chamam a atenção para o fato de que todos esses conteúdos, identificados nas questões da prova que elaboramos, foram suscitados nos estudos realizados pelos estudantes no desenvolvimento das atividades de modelagem matemática no ano anterior. Além disso, trata-se de conteúdos curriculares indicados pelos PCN para esse nível de escolaridade, o que contribui para firmar a possibilidade de utilizar 
a modelagem matemática no âmbito do ensino e aprendizagem de Matemática nos anos iniciais do ensino fundamental.

\section{Discussões finais}

As formas de avaliar a aprendizagem dos alunos quando envolvidos em atividades de modelagem matemática são ainda pouco discutidas na literatura. De modo geral, as pesquisas, por meio de alguns critérios, fazem inferências sobre a aprendizagem dos alunos a partir de ações e/ ou manifestações apresentadas por eles. Ter indicativos de que o aluno aprendeu, e aprendeu aquela Matemática que emergiu das atividades de modelagem, corresponde, sem dúvida, à expectativa que se tem quando da introdução dessas atividades nas aulas de Matemática.

Atividades de modelagem matemática, em geral, não estão focadas na abordagem de um conteúdo específico - como se costuma observar em "exercícios de fixação", frequentemente utilizados nas aulas de Matemática -, mas na obtenção de um modelo matemático que seja capaz de responder ao problema proposto para investigação. E é este caminhar que suscita a abordagem de diferentes conteúdos matemáticos, conforme a situação e os sujeitos envolvidos.

Como consequência, observamos uma diversidade de representações usadas pelos estudantes para os modelos matemáticos, cuja linguagem utilizada é característica dos anos iniciais do ensino fundamental.

Nesse sentido, foi possível a abordagem de uma diversidade de conteúdos matemáticos, cuja aprendizagem pode ser inferida a partir do desempenho dos estudantes nas questões associadas à Prova Brasil, que lhes foram propostas.

Não podemos, entretanto, assegurar que o desempenho dos alunos na resolução das questões é decorrência imediata de seu envolvimento com as atividades de modelagem. Outros fatores também influenciaram nesse resultado, cada um à sua maneira e com sua intensidade, como as aulas com as professoras da turma, o convívio com outras pessoas e situações cotidianas, entre outros.

Contudo, ao escolher questões que contemplam conteúdos abordados no desenvolvimento das atividades de modelagem matemática, não podemos negar a existência de uma relação entre o desenvolvimento das atividades de modelagem e o desempenho dos alunos na prova.

Nesse sentido, parece se configurar uma situação que sinaliza certa estabilidade na aprendizagem dos alunos em relação aos conteúdos abordados mediante atividades de modelagem matemática. Essa já representa uma justificativa para a inclusão de atividades desse tipo nas aulas de Matemática. Assim, se o programa do Observatório da Educação tem como meta contribuir para a configuração de situações para a sala de aula, envolvendo alunos e professores, que possam trazer melhorias educacionais e cujo reflexo também se evidencie no desempenho dos alunos em avaliações de larga escala, a pesquisa que desenvolvemos se alinha com essa expectativa. 


\section{Referências bibliográficas}

ALMEIDA, L. M. W. Um olhar semiótico sobre modelos e modelagem: metáforas como foco de análise. Zetetiké, Campinas, v. 18, número temático, 2010.

ALMEIDA, L. M. W.; BRITO, Dirceu dos Santos. Atividades de modelagem matemática: que sentido os alunos podem lhe atribuir? Ciência \& Educação, Bauru, v. 11, n. 3, p. 483-498, 2005.

ALMEIDA, L. M. W.; DIAS, Michele Regiane. Um estudo sobre o uso da modelagem matemática como estratégia de ensino e aprendizagem. Bolema: Boletim de Educação Matemática, Rio Claro, n. 22, p. 19-35, 2004.

ALMEIDA, L. M. W. de; SILVA, Karina Pessôa da; VERTUAN, Rodolfo Eduardo. Modelagem Matemática na educação básica. São Paulo: Contexto, 2012. 157 p.

BARBOSA, J. C. Modelagem matemática: concepções e experiências de futuros professores. 2001. 253 f. Tese (Doutorado em Educação Matemática) - Instituto de Geociências e Ciências Exatas, Universidade Estadual Paulista, Rio Claro, 2001.

BARBOSA, Jonei Cerqueira. Modelagem matemática: O que é? Por quê? Como? Veritati, Salvador, n. 4, p. 73-80, 2004.

BASSANEZI, Rodney Carlos. Ensino-aprendizagem com modelagem matemática: uma nova estratégia. 2. ed. São Paulo: Contexto, 2004. 389 p.

BLUM, W. Mathematical Modelling in Mathematics education and instruction. In: BREITEIG, Trygve; HUNTLEY, Ian; KAISER, Gabriele Messmer (Ed.). Teaching and learning Mathematics in context. London: Ellis Horwood, 1993. p. 3-14.

BLUM, W. Can Modelling be taught and learnt? Some answers from empirical research. In: KAISER, Gabriele et al. (Ed.). Trends in teaching and learning of Mathematical Modelling: ICTMA 14. New York:

Springer, 2011. p. 15-30.

BLUM, W.; BORROMEO FERRI, Rita. Mathematical Modelling: can it be taught and learnt? Journal of Mathematical Modelling and Aplication, Blumenau, v. 1, n. 12, p. 45-58, 2009.

BORROMEO FERRI, Rita. Estabelecendo conexões com a vida real na prática da aula de Matemática. Educação e Matemática, Lisboa, n. 110, p. 19-25, nov./dez. 2010. 
Reflexões a respeito do uso da modelagem matemática em aulas nos anos

D'AMBRÓSIO, Ubiratan. Mathematical Modelling: cognitive, pedagogical, historical and political dimensions. Journal of Mathematical Modelling and Application, Blumenau, v. 1, n. 1, p. 8998, 2009 .

D'AMORE, Bruno. Epistemologia, didática da Matemática e práticas de ensino. Bolema: Boletim de Educação Matemática, Rio Claro, n. 28, p. 179-205, 2007.

DIAS, Josete Leal; CHAVES, Maria Isaura de Albuquerque. Diálogos com/na Modelagem Matemática nas séries iniciais. In: CONFERÊNCIA NACIONAL SOBRE MODELAGEM NA EDUCAÇÃO MATEMÁTICA, 6., 2009, Londrina. Anais... Londrina: UEL, 2009.

DOERR, Helen M.; LESH, Richard. Models and modelling perspectives on teaching and learning Mathematics in the twenty-first century. In: KAISER, Gabriele et al. (Ed.). Trends in teaching and learning of Mathematical Modelling: ICTMA 14. New York: Springer, 2011. p. 247268.

KLÜBER, Tiago Emanuel; BURAK, Dionísio. Bases epistemológicas e implicações para práticas de Modelagem matemática em sala de aula. In: SEMINÁRIO INTERNACIONAL DE PESQUISA EM EDUCAÇÃO MATEMÁTICA, 4., Brasília. Anais... Brasília: Sociedade Brasileira de Educação Matemática, 2009.

LESH, Richard. Tools, researchable issues \& conjectures for investigating: what it means to understanding statistics (or other topics) meaningfully. Journal of Mathematical Modelling and Application, Blumenau, v. 1, n. 2, p. 16-48, 2010.

LUNA, Ana Virginia de Almeida; ALVES, Josélia. Modelagem matemática: as interações discursivas de crianças da $4^{a}$ série a partir de um estudo sobre anorexia. In: CONFERÊNCIA NACIONAL SOBRE MODELAGEM NA EDUCAÇÃO MATEMÁTICA, 5., 2007, Ouro Preto. Anais... Ouro Preto: UFOP, 2007, p. 855-876.

ROSA, Milton; OREY, Daniel Clark. A modelagem como um ambiente de aprendizagem para a conversão do conhecimento matemático. Bolema: Boletim de Educação Matemática, Rio Claro, v. 26, n. 42A, p. 261-290, abr. 2012.

SILVEIRA, Everaldo. Modelagem matemática em Educação no Brasil: entendendo o universo de teses e dissertações. 2007. $197 \mathrm{f}$. Dissertação (Mestrado em Educação) - Universidade Federal do Paraná, Curitiba, 2007. 
Emerson Tortola é mestrando no Programa de Pós-Graduação em Ensino de Ciências e Educação Matemática da Universidade Estadual de Londrina (UEL), Londrina, Paraná, Brasil.

emersontortola@hotmail.com

Lourdes Maria Werle de Almeida, doutora em Engenharia de Produção pela Universidade Federal de Santa Catarina (UFSC), é professora do Programa de Pós-Graduação em Ensino de Ciências e Educação Matemática da Universidade Estadual de Londrina (UEL), Londrina, Paraná, Brasil.

lourdes.maria@sercomtel.com.br

Recebido em 31 de agosto de 2012.

Aprovado em 5 de março de 2013. 